\title{
Uso de tecnologias educacionais no processo de ensino sobre ressuscitação cardiopulmonar para equipe de enfermagem
}

\author{
Use of educational technologies in the teaching process about cardiopulmonary \\ resuscitation for nursing staff
}

Uso de las tecnologías educativas en el proceso de enseñanza de la reanimación cardiopulmonar para el personal de enfermeira

Sara Teixeira Braga1*, Yasmin Ventura Andrade Carneiro ${ }^{1}$, Suzete Gonçalves Caçula ${ }^{1}$, Lorena Farias Rodrigues Correia ${ }^{1}$, Brunna Nayara Alves Souza Rolim de Sena², lasminny Loiola Teixeira ${ }^{3}$, Luis Rafael Leite Sampaio ${ }^{1}$, Rayane Moreira de Alencar ${ }^{1}$, Maria Corina Amaral Viana1, Woneska Rodrigues Pinheiro'.

\section{RESUMO}

Objetivo: Identificar na literatura evidências acerca da contribuição das tecnologias educacionais no processo de ensino sobre ressuscitação cardiopulmonar para equipe de enfermagem. Métodos: Trata-se de uma revisão integrativa da literatura, com caráter descritivo e abordagem qualitativa. $A$ busca foi realizada no conjunto das seguintes bases de dados eletrônicas: BDENF, LILACS, MEDLINE via Pubmed, SCOPUS, CINAHL e Biblioteca SciELO. Utilizou-se os descritores do MeSH: "Nurses"; "Continuing education"; "Cardiopulmonary resuscitation" e os DeCS: "Ensino"; "Enfermeiros"; "Avaliação de treinamentos"; "Educação continuada"; "Ressuscitação cardiopulmonar". Combinados entre si com o operador booleano AND. Resultados: Quanto à estratégia tecnológica utilizada para ensino, se destacou a simulação, produção tecnológica por vídeo-aula, questionário e checklist, considerando que o uso de tecnologias educacionais no processo de ensino-aprendizagem é considerado um grande avanço, pois as tecnologias fazem parte do cotidiano, gerando assim interesse nos participantes e promovendo melhorias no processo de capacitação. Considerações finais: A influência destas tecnologias educacionais para aprimoramento de saberes sobre ressuscitação cardiopulmonar e repercussão na qualidade da assistência resultou no aprimoramento de conhecimentos e desenvolvimento de habilidades, avaliação de impacto, de competências e atitudes, registrando impacto positivo das tecnologias utilizadas como estratégia de aprendizagem.

Palavras-chave: Ensino, Equipe de enfermagem, Tecnologia educacional, Ressuscitação cardiopulmonar.

\begin{abstract}
Objective: To identify in the literature evidence about the contribution of educational technologies in the teaching process about cardiopulmonary resuscitation for nursing staff. Methods: This is an integrative literature review, with descriptive character and qualitative approach. The search was conducted in the following electronic databases: BDENF, LILACS, MEDLINE via Pubmed, SCOPUS, CINAHL and SciELO Library. The MeSH descriptors were used: "Nurses"; "Continuing education"; "Cardiopulmonary resuscitation" and the DeCS: "Teaching"; "Nurses"; "Training evaluation"; "Continuing education"; "Cardiopulmonary resuscitation". Combined with the Boolean operator AND. Results: As for the

1 Universidade Regional do Cariri (URCA), Crato - CE. *E-mail: sara.braga@urca.br

2 Faculdade do Vale do Jaguaribe (FVJ), Aracati - CE.

${ }^{3}$ Centro Universitário Leão Sampaio (UNILEÃO), Juazeiro do Norte - CE.
\end{abstract}


technological strategy used for teaching, the simulation, technological production by video lesson, questionnaire, and checklist stood out, considering that the use of educational technologies in the teachinglearning process is considered a great advance, because the technologies are part of everyday life, thus generating interest in the participants and promoting improvements in the training process. Final considerations: The influence of these educational technologies for the improvement of knowledge about cardiopulmonary resuscitation and repercussion on the quality of care resulted in the improvement of knowledge and development of skills, impact evaluation, competencies, and attitudes, registering a positive impact of the technologies used as a learning strategy.

Keywords: Teaching, Nursing team, Educational technology, Cardiopulmonary resuscitation.

\section{RESUMEN}

Objetivo: Identificar en la literatura las evidencias sobre la contribución de las tecnologías educativas en el proceso de enseñanza sobre resucitación cardiopulmonar para el equipo de enfermería. Métodos: Se trata de una revisión bibliográfica integradora, de carácter descriptivo y enfoque cualitativo. La búsqueda se realizó en las siguientes bases de datos electrónicas: BDENF, LILACS, MEDLINE vía Pubmed, SCOPUS, CINAHL y SciELO Library. Se utilizaron los descriptores MeSH: "Nurses"; "Continuing education"; "Cardiopulmonary resuscitation" y los DeCS: "Teaching"; "Nurses"; "Training assessment"; "Continuing education"; "Cardiopulmonary resuscitation". Combinado con el operador booleano AND. Resultados: En cuanto a la estrategia tecnológica utilizada para la enseñanza, se destacaron la simulación, la producción tecnológica por video lección, el cuestionario y la lista de cotejo, considerando que el uso de las tecnologías educativas en el proceso de enseñanza-aprendizaje es considerado un gran avance, porque las tecnologías forman parte de la vida cotidiana, generando así interés en los participantes y promoviendo mejoras en el proceso de formación. Consideraciones finales: La influencia de estas tecnologías educativas para la mejora de los conocimientos sobre la reanimación cardiopulmonar y la repercusión en la calidad de la atención se tradujo en la mejora de los conocimientos y el desarrollo de habilidades, la evaluación del impacto, las aptitudes y las actitudes, registrando un impacto positivo de las tecnologías utilizadas como estrategia de aprendizaje.

Palabras clave: Enseñanza, Equipo de enfermería, Tecnología educativa, Reanimación cardiopulmonar.

\section{INTRODUÇÃO}

Entre os agravos cardiovasculares a Parada Cardiorrespiratória (PCR) representa o evento mais grave ameaçador à vida. É caracterizado pela suspensão da atividade do coração expressa pela inexistência de sinais de circulação, podendo ser uma intercorrência inesperada ou uma evolução do quadro clínico de um paciente em estado grave e que configura situação de iminência de morte (PINHEIRO WR, 2020)

Nos Estados Unidos e Canadá cerca de 350.000 pessoas/ano sofrem uma PCR e recebem tentativa de reanimação. No Brasil, estima-se que, anualmente, ocorra em torno de 200 mil PCR e 50\% deste total acontece no ambiente intra-hospitalar. Quanto à sobrevida geral é de $18,4 \%$, os autores descrevem que o ritmo inicial detectado, quando não é passível de choque varia entre 10,5\%, e 49\%, se o ritmo for passível de choque (PINHEIRO WR, 2020; SILVA AC, 2016).

Diante da magnitude do problema, pensando em evitar um desfecho desastroso para pacientes vítimas de PCR e salvar o maior número de pessoas acometidas por este evento, a Liga Internacional de Comitês de Ressuscitação (ILCOR), em colaboração com a Associação Americana do Coração (AHA), produziram os protocolos, conhecidos como "guidelines", os quais são atualizados a cada cinco anos e padronizam, em todo o mundo, as manobras de Reanimação Cardiopulmonar (RCP), orientando as medidas a serem adotadas no Suporte Básico de Vida (BLS) e no suporte avançado de vida cardiológico (ACLS, advanced cardiac life support) (AMERICAN HEART ASSOCIATION, 2020). 
O reconhecimento pregresso das causas de PCR, com a devida orientação e mediação para cada cenário clínico, com ênfase nos cuidados após o retorno à circulação espontânea, trouxe evolução nas repercussões, contribuindo para melhor o prognóstico das vítimas. Segundo autores a padronização e a organização da assistência médica melhoraram ainda mais com o desenvolvimento de protocolos e algoritmos internacionais (BERNOCHE C, et al., 2019).

Assim, a RCP consiste em uma estratégia de cuidados avançados, ordenados, adotada frente à situação de PCR. Representa o procedimento emergencial padrão que envolve uma série de medidas que objetivam a manutenção do fluxo de sangue oxigenado aos órgãos vitais, principalmente cérebro e coração. As medidas assumidas mediante a PCR requerem intervenções coordenadas, que no suporte avançado de vida compreendem as compressões torácicas, manejo de via aérea, monitorização eletrocardiográficas, desfibrilação externa manual ou automática, acesso venoso e uso de drogas (BERNOCHE C, et al., 2019).

Dentre os profissionais que compõe a equipe de saúde na assistência à vítima de PCR, encontra-se o enfermeiro e os técnicos de enfermagem que são os responsáveis por passarem maior parte do tempo ao lado do paciente, esses, precisam estar preparados para prestar a assistência contínua (PIMENTEL TGB, 2019).

A qualificação do profissional da saúde tem sido realizada por meio de diferentes estratégias educativas e muitas vezes mediada por tecnologias educacionais. Entende-se por tecnologia educacional, como sendo os princípios do conhecimento científico, da tecnologia e do comportamento aplicados para resolução efetiva de problemas educacionais de modo sistemático e metodológico (KOBAYASHI RM e ARAÚJO GD, 2019).

A tecnologia educacional tem sido utilizada em diversos programas de aprendizagem de enfermeiros, tendo como foco o estudo autodirigido, o principal objetivo é atender ao ensino extra sala de aulas e à limitação de tempo. De acordo com os autores, o desenvolvimento de habilidades aplicando o conhecimento adquirido no exercício prático profissional, a simulação de alta fidelidade tem sido uma das escolhas bastantes presentes nos processos educativos (KOBAYASHI RM e ARAÚJO GD, 2019).

A tecnologia educacional é desenvolvida a partir do uso de materiais multimídias e de interações virtuais para capacitar profissionais na área da enfermagem, com o objetivo de proporcionar maior segurança e promover o aperfeiçoamento do desempenho e da competência profissional, além de facilitar o processo educativo e melhoria na assistência de enfermagem (SANGUINO GZ, 2019).

Essas tecnologias educacionais se destacam pela avaliação e aplicabilidade na prática, aferindo-se a evidências de impacto no desempenho do participante, de sua equipe e da organização. A aprendizagem relaciona-se ao grau de compreensão e retenção dos conteúdos ensinados por meio das tecnologias, buscando o alcance dos objetivos e comportamentos observáveis no trabalho (KOBAYASHI RM e ARAÚJO GD, 2019).

Neste sentido, se faz relevante identificar as contribuições das tecnologias educacionais no processo de ensino sobre ressuscitação cardiopulmonar para equipe de enfermagem. Os resultados desta pesquisa contribuirão de parâmetros para o desenvolvimento de conhecimentos em tecnologias de ensino para 0 desenvolvimento de habilidade e atitudes da equipe de enfermagem na assistência à vítima de PCR.

\section{MÉTODOS}

Para o levantamento dos estudos foi realizada uma revisão integrativa de literatura, que consente na construção de uma análise ampla da literatura, contribuindo para discussões sobre métodos e resultados de pesquisas, assim como reflexões sobre a realização de futuros estudos (SOUZA MT, et al., 2010).

O estudo compreendeu as seguintes etapas: I) detecção do tema e seleção da questão norteadora; II) estabelecimento de critérios para inclusão e exclusão do estudo e busca na literatura; III) detectar as informações a serem extraídas dos estudos selecionados e agrupamento dos estudos; IV) apreciação dos estudos incluídos; V) explanação dos resultados; VI) descrição da revisão e síntese do conhecimento (MENDES KDS, et al., 2008). 
Para formulação da pergunta de revisão, foi utilizada a estratégia P.V.O., sendo formulada a seguinte estratégia que pode ser observada no (Quadro 1). Teve-se como questão norteadora da revisão: Quais as contribuições das tecnologias educacionais no processo de ensino sobre ressuscitação cardiopulmonar e a sua repercussão na qualidade da assistência?

Quadro 1 - Estratégia de busca PVO nas bases de dados.

\begin{tabular}{|c|c|c|c|}
\hline Sigla & Conteúdo & $\begin{array}{l}\text { MeSH termos/ } \\
\text { LILACS/BDENF/CINAHL, } \\
\text { MEDLINE/SciELO }\end{array}$ & $\begin{array}{c}\text { DeCS Termos/ } \\
\text { scopus }\end{array}$ \\
\hline $\mathbf{P}$ & $\begin{array}{l}\text { Profissionais da } \\
\text { saúde }\end{array}$ & Nurses & Enfermeiros \\
\hline & & $A N D$ & $A N D$ \\
\hline v & $\begin{array}{l}\text { Tecnologias } \\
\text { educativas }\end{array}$ & Continuing education & $\begin{array}{l}\text { Ensino; Avaliação de } \\
\text { treinamentos; Educação } \\
\text { continuada }\end{array}$ \\
\hline & & $A N D$ & $A N D$ \\
\hline 0 & $\begin{array}{l}\text { Ressuscitação } \\
\text { cardiopulmonar }\end{array}$ & $\begin{array}{l}\text { Cardiopulmonary } \\
\text { resuscitation }\end{array}$ & Ressuscitação cardiopulmonar \\
\hline
\end{tabular}

Fonte: Braga ST, et al., 2021.

A busca dos artigos e seleção da amostra ocorreu em pares por dois revisores de forma independente, nos meses de abril e maio do ano de 2021. O universo pesquisado foram os estudos indexados no Portal de Periódicos da Capes, no conjunto das seguintes bases de dados eletrônicas: Base de Dados de Enfermagem (BDENF), Literatura Latino-Americana e do Caribe em Ciências da Saúde (LILACS), Medical Literature Analysis and Retrieval System (MEDLINE) via Pubmed, SCOPUS Preview, Cumulative Index to Nursing and Allied Health Literature (CINAHL) e Biblioteca Scientific Electronic Library Online (SciELO).

Utilizou-se os descritores do Medical Subject Headdings (MeSH) para as bases MEDLINE, LILACS, SciELO, CINAHL e BDENF combinadas entre si com o operador booleano AND. Além dos descritores em ciências da saúde (DeCS) próprios para a base SCOPUS.

Para as bases BDENF, CINAHL, LILACS, MEDLINE e SciELO, foram utilizadas as estratégias de busca: "Nurses" AND "Continuing education" AND "Cardiopulmonary resuscitation". Para a base SCOPUS foram utilizadas as estratégias de busca: "Ensino" AND "Enfermeiros" AND "Avaliação de treinamentos" OR "Educação continuada" AND "Ressuscitação cardiopulmonar".

Em suma, foram identificados 487 estudos, dos quais após leitura exaustiva de título e resumo, foram excluídos 404 artigos, que não se relacionavam com o objetivo da pesquisa, após a realização da leitura na íntegra totalizou em 83 artigos, destes 10 eram repetidos, 12 estudos indisponíveis e 37 estudos de outra natureza, restando 24 estudos como critérios de elegibilidade, destes 09 não responderam ao objetivo de pesquisa, sendo incluídos 15 estudos considerados relevantes para a revisão integrativa.

Os artigos foram submetidos a um processo de filtragem constituído pelos critérios de inclusão: artigos completos e originais disponíveis na íntegra; publicados em português, inglês ou espanhol e que se relacionassem com o ensino para equipes de enfermagem sobre ressuscitação cardiopulmonar mediados por tecnologias educacionais. Foram excluídos os estudos de revisão, duplicados, editoriais e os que não abordassem a temática investigada. Não foi preestabelecido uma delimitação temporal a fim de encontrar 0 maior número de artigos relacionados ao tema. 
Para a organização dos estudos foram observadas as recomendações da Preferred Reporting ltems for Systematic Rewiew and Meta-Analyses (PRISMA), o qual está descrito na (Figura 1).

Figura 1- Fluxograma de seleção dos estudos, adaptado segundo Preferred Reporting Itens for Systematic Review and Meta-Analyses (PRISMA).

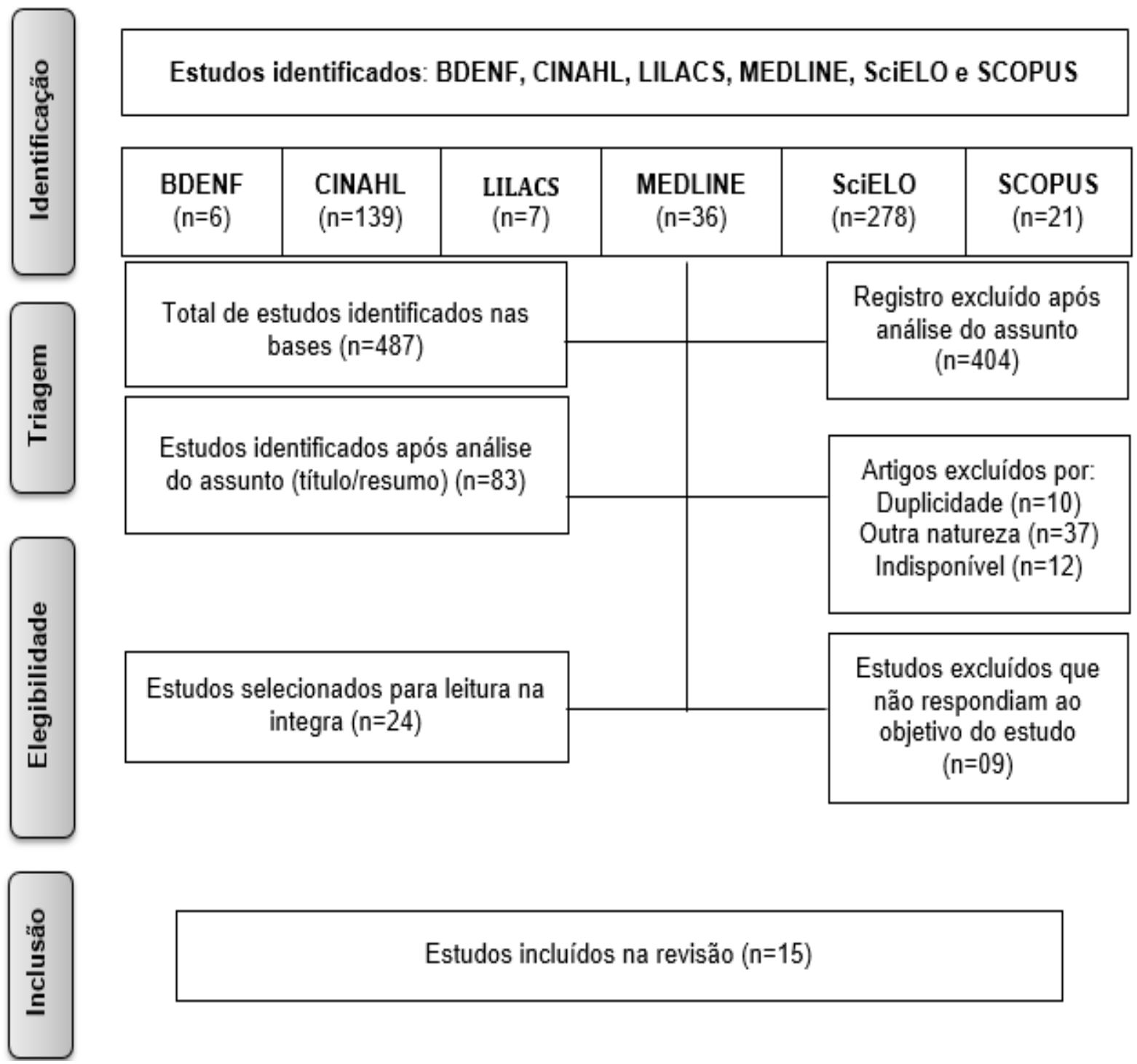

Fonte: Braga ST, et al., 2021.

Os estudos foram categorizados conforme os sete níveis de evidência: nível 1, revisão sistemática ou metanálise de ensaios clínicos randomizados controlados / diretrizes clínicas que contenham os estudos de revisão supracitados; nível 2, ensaio clínico randomizado controlado e bem delineado; nível 3, ensaio clínico controle, mas sem randomização; nível 4, estudos de caso-controle ou coorte bem delineados; nível 5, revisão sistemática de estudos descritivos e qualitativos; nível 6, estudos descritivos ou qualitativos; e nível 7 opinião de especialistas (MELNYK T, et al., 2009).

\section{RESULTADOS E DISCUSSÃO}

Os achados foram descritos e discutidos de forma crítica e reflexiva, conciliando com as publicações relacionadas ao tema de estudo, representado no (Quadro 2). 
Quadro 2 - Categorização dos estudos primários incluídos na revisão ( $\mathrm{N}=15)$.

\begin{tabular}{|c|c|c|c|c|c|c|c|c|}
\hline $\mathbf{N}^{\circ}$ & $\begin{array}{c}\text { Autor/Ano/ } \\
\text { País/ Base de } \\
\text { dados indexada }\end{array}$ & Título & Objetivo & $\begin{array}{l}\text { Tipo de } \\
\text { estudo }\end{array}$ & $\begin{array}{c}\text { Estratégia } \\
\text { Tecnológica } \\
\text { para ensino }\end{array}$ & Resultados & Conclusões & $\begin{array}{l}\text { Níveis de } \\
\text { evidências }\end{array}$ \\
\hline 1 & $\begin{array}{l}\text { IRELAND S, et al., } \\
\text { 2020/ Australia/ } \\
\text { ScOPUS }\end{array}$ & $\begin{array}{l}\text { Emergency nurses' } \\
\text { experience of adult basic } \\
\text { and advanced life support } \\
\text { workstations as a support } \\
\text { strategy for clinical } \\
\text { practice in the emergency } \\
\text { department }\end{array}$ & $\begin{array}{l}\text { Relatar a percepção da } \\
\text { experiência das enfermeiras } \\
\text { após } 0 \text { atendimento nas } \\
\text { estações de trabalho }\end{array}$ & $\begin{array}{l}\text { Estudo } \\
\text { descritivo, } \\
\text { qualitativo }\end{array}$ & Simulação & $\begin{array}{l}\text { Um total de } 143 \text { enfermeiras } \\
\text { consentiu em participar, a } \\
\text { maioria relatou aumento de } \\
\text { conhecimentos e habilidades } \\
(93,7 \%) \text {, confiança }(91,9 \%) \text { e } \\
\text { que praticavam habilidades } \\
\text { (91,9\%) durante a participação } \\
\text { no posto de trabalho. }\end{array}$ & $\begin{array}{lr}\text { A educação } & \text { permanente } \\
\text { foi } & \text { altamente } \\
\text { considerada } & \text { pelos } \\
\text { enfermeiros } & \text { de } \\
\text { emergência. } & \end{array}$ & 4 \\
\hline 2 & $\begin{array}{l}\text { LIMA SG, et al., } \\
\text { 2009/ Brasil/ LILACS }\end{array}$ & $\begin{array}{l}\text { Educação Permanente em } \\
\text { SBV e SAVC: Impacto no } \\
\text { Conhecimento ros } \\
\text { Profissionais } \\
\text { Enfermagem }\end{array}$ & $\begin{array}{l}\text { Avaliar o impacto de um } \\
\text { programa permanente de } \\
\text { treinamento em SBV e SAV no } \\
\text { conhecimento dos profissionais } \\
\text { de enfermagem }\end{array}$ & $\begin{array}{l}\text { Estudo } \\
\text { descritivo, } \\
\text { qualitativo }\end{array}$ & Simulação & $\begin{array}{l}\text { Foram avaliados } 213 \\
\text { profissionais. As maiores } \\
\text { deficiências foram relacionadas } \\
\text { à abordagem inicial das vias } \\
\text { aéreas, aos cuidados pós- } \\
\text { ressuscitação e à técnica de } \\
\text { massagem cardíaca externa. }\end{array}$ & $\begin{array}{l}\text { O programa de } \\
\text { treinamento permanente } \\
\text { em SBV e SAV foi } \\
\text { satisfatório ao nível de } \\
\text { conhecimento r dos } \\
\text { profissionais } \\
\text { enfermagem. }\end{array}$ & 4 \\
\hline 3 & $\begin{array}{l}\text { MEIRA JÚNIOR LE, } \\
\text { et al., 2016/ Brasil/ } \\
\text { LILACS }\end{array}$ & $\begin{array}{l}\text { Avaliação de treinamento } \\
\text { em suporte básico de vida } \\
\text { para médicos e } \\
\text { enfermeiros da atenção } \\
\text { primária }\end{array}$ & $\begin{array}{l}\text { Avaliar os conhecimentos e } \\
\text { habilidades sobre reanimação } \\
\text { cardiopulmonar antes e após a } \\
\text { capacitação em Suporte Básico } \\
\text { de Vida (SBV) }\end{array}$ & $\begin{array}{l}\text { Estudo } \\
\text { quase- } \\
\text { experimental }\end{array}$ & Checklist & $\begin{array}{l}\text { Participaram do estudo } 32 \\
\text { profissionais. Após a } \\
\text { capacitação, á média de acertos } \\
\text { na avaliação teórico-prática } \\
\begin{array}{l}\text { apresentou } \\
\text { significativo }(p<0,001) \text { aumento }\end{array}\end{array}$ & $\begin{array}{l}\text { Registrou-se impacto } \\
\text { positivo da capacitação } \\
\text { em SBV para os } \\
\text { profissionais da atenção } \\
\text { primária. }\end{array}$ & 3 \\
\hline 4 & $\begin{array}{l}\text { ALVES MG, et al., } \\
\text { 2019/ Brasil/ } \\
\text { LILACS }\end{array}$ & $\begin{array}{l}\text { Construção e validação de } \\
\text { vídeo-aula sobre } \\
\text { Ressuscitação } \\
\text { cardiopulmonar }\end{array}$ & $\begin{array}{l}\text { Construir e validar um objeto } \\
\text { contemporâneo virtual de } \\
\text { ensino, vídeo-aula, sobre } \\
\text { ressuscitação cardiopulmonar } \\
\text { no adulto em suporte básico de } \\
\text { vida com o uso do desfibrilador } \\
\text { externo automático no ambiente } \\
\text { hospitalar. }\end{array}$ & $\begin{array}{l}\text { Estudo } \\
\text { quase- } \\
\text { experimental }\end{array}$ & $\begin{array}{l}\text { Produção de } \\
\text { vídeo-aula. }\end{array}$ & $\begin{array}{l}\text { A validação do roteiro/script e } \\
\text { storyboard foi alcançada a } \\
\text { concordância inter-avaliadores, } \\
\text { de acordo com Landis e Kock, } \\
\text { classificada em "concordância } \\
\text { moderada", com AC1 } 1=0,59 \text { e } \\
p<0,0001 \text {. }\end{array}$ & $\begin{array}{l}\text { A vídeo-aula construída } \\
\text { e validada representa } \\
\text { importante estratégia } \\
\text { contemporânea } \\
\text { adequada para aplicação } \\
\text { no processo de ensino- } \\
\text { aprendizagem. }\end{array}$ & 3 \\
\hline 5 & $\begin{array}{l}\text { ASSALIN AC, et al., } \\
\text { 2019/ Brasil/ LILACS }\end{array}$ & $\begin{array}{l}\text { Programa de Treinamento } \\
\text { Teórico/Prático In Loco } \\
\text { para Enfermagem Acerca } \\
\text { das Manobras Básicas em } \\
\text { Ressuscitação } \\
\text { Cardiopulmonar }\end{array}$ & $\begin{array}{l}\text { Avaliar um programa de } \\
\text { treinamento teórico/prático in } \\
\text { loco para técnicos e auxiliares } \\
\text { de enfermagem sobre } \\
\text { manobras básicas em } \\
\text { ressuscitação cardiopulmonar }\end{array}$ & $\begin{array}{l}\text { Estudo } \\
\text { quase- } \\
\text { experimental }\end{array}$ & $\begin{array}{l}\text { Questionário/Si } \\
\text { mulação }\end{array}$ & $\begin{array}{l}\text { O maior desempenho foi no } \\
\text { reconhecimento da parada } \\
\text { cardiorrespiratória (PCR), } 83,3 \\
\% \text { para auxiliares e } 83,6 \% \text { para } \\
\text { técnicos. }\end{array}$ & $\begin{array}{l}\text { A intervenção realizada } \\
\text { mostrou-se eficaz, já que } \\
\text { houve aumento } \\
\text { significativo nos acertos } \\
\text { do pós-teste. }\end{array}$ & 3 \\
\hline
\end{tabular}




\begin{tabular}{|c|c|c|c|c|c|c|c|c|}
\hline $\mathbf{N}^{\circ}$ & $\begin{array}{c}\text { Autor/Ano/ } \\
\text { País/ Base de } \\
\text { dados indexada }\end{array}$ & Título & Objetivo & $\begin{array}{l}\text { Tipo de } \\
\text { estudo }\end{array}$ & $\begin{array}{l}\text { Estratégia } \\
\text { Tecnológica } \\
\text { para ensino }\end{array}$ & Resultados & Conclusões & $\begin{array}{l}\text { Níveis de } \\
\text { evidências }\end{array}$ \\
\hline 6 & $\begin{array}{l}\text { BERTOGLIO VM, et } \\
\text { al., 2008/ Brasil/ } \\
\text { LILACS }\end{array}$ & $\begin{array}{l}\text { Tempo decorrido do } \\
\text { treinamento em parada } \\
\text { cardiorrespiratória e o } \\
\text { impacto no conhecimento } \\
\text { teórico de enfermeiros. }\end{array}$ & $\begin{array}{l}\text { Avaliar o conhecimento de } \\
\text { enfermeiros referente ao } \\
\text { atendimento em parada } \\
\text { cardiorrespiratória, relacionando } \\
\text { esses resultados com o tempo } \\
\text { decorrido da capacitação. }\end{array}$ & $\begin{array}{l}\text { Estudo } \\
\text { descritivo, } \\
\text { qualitativo }\end{array}$ & Simulação & $\begin{array}{l}\text { A amostra foi dividida em dois } \\
\text { grupos, um com monitor } \\
\text { cardíaco e desfibrilador e no } \\
\text { outro grupo sem esses } \\
\text { equipamentos. Demonstrou-se } \\
\text { que em ambos os grupos } \\
\text { avaliados o treinamento em } \\
\text { PCR foi efetivo. }\end{array}$ & $\begin{array}{l}\text { Estratégias de educação } \\
\text { continuada devem ser } \\
\text { incentivadas e } \\
\text { mantidas } \\
\text { sistematicamente para } \\
\text { garantir o melhor } \\
\text { desempenho da equipe. }\end{array}$ & 4 \\
\hline 7 & $\begin{array}{l}\text { VEIGA VC, et al., } \\
\text { 2013/ Brasil/ LILACS }\end{array}$ & $\begin{array}{l}\text { Atuação do Time de } \\
\text { Resposta Rápida no } \\
\text { processo educativo de } \\
\text { atendimento da parada } \\
\text { cardiorrespiratória }\end{array}$ & $\begin{array}{lrr}\text { Avaliar o conhecimento da } & \text { da } \\
\text { equipe } & \text { (enfermagem } & \text { e } \\
\text { fisioterapia) no reconhecimento } & \text { no recotamento da PCR e mostrar } \\
\text { e tratame } \\
\text { um modelo de gestão do time } \\
\text { de resposta rápida no processo } \\
\text { educacional. }\end{array}$ & $\begin{array}{l}\text { Estudo } \\
\text { descritivo, } \\
\text { qualitativo }\end{array}$ & Questionário & $\begin{array}{l}\text { No grupo de enfermeiros, a nota } \\
\text { média no pré-teste foi de } 5,83 \pm \\
1,95 \text { e } 8,87 \pm 1,25 \text {, no pós-teste. }\end{array}$ & $\begin{array}{l}\text { Os resultados mostram } \\
\text { deficiência r no } \\
\text { conhecimento da equipe } \\
\text { multiprofissional diante } \\
\text { das situações de PCR. }\end{array}$ & 4 \\
\hline 8 & $\begin{array}{l}\text { PISCIOTTANI F, et } \\
\text { al., 2017/ Brasil/ } \\
\text { CINAHL }\end{array}$ & $\begin{array}{l}\text { In situ simulation in } \\
\text { cardiopulmonary } \\
\text { resuscitation: implications } \\
\text { for permanent nursing } \\
\text { education }\end{array}$ & $\begin{array}{l}\text { Comparar o desenvolvimento } \\
\text { de competências para } \\
\text { ressuscitação cardiopulmonar } \\
\text { entre grupos com } \\
\text { periodicidades de intervenção } \\
\text { diferentes, utilizando a } \\
\text { simulação in situ como método } \\
\text { de ensino aprendizagem. }\end{array}$ & $\begin{array}{c}\text { Estudo } \\
\text { experimental } \\
\text { com } \\
\text { abordagem } \\
\text { quantitativa }\end{array}$ & Simulação & $\begin{array}{l}\text { Determinaram o intervalo de } \\
\text { formação periódica com o uso } \\
\text { da simulação in situ, para o } \\
\text { desenvolvimento } \\
\text { competências em RCP. }\end{array}$ & $\begin{array}{l}\text { Espera-se que os } \\
\text { instrumentos de coleta } \\
\text { avaliem o conhecimento } \\
\text { e as habilidades para } \\
\text { RCP, além da percepção } \\
\text { dos participantes em } \\
\text { relação às suas } \\
\text { competências no no } \\
\text { atendimento à parada } \\
\text { cardiorrespiratória } \\
\text { (PCR). }\end{array}$ & 2 \\
\hline 9 & $\begin{array}{l}\text { BISHOP R, et al., } \\
\text { 2018/ EUA/ CINAHL }\end{array}$ & $\begin{array}{l}\text { Automated Audiovisual } \\
\text { Feedback in } \\
\text { Cardiopulmonary } \\
\text { Resuscitation Training: } \\
\text { Improving Skills in } \\
\text { Pediatric } \\
\text { Intensive Care Nurses }\end{array}$ & $\begin{array}{l}\text { Determinar se o treinamento } \\
\text { intermitente breve em } \\
\text { ressuscitação cardiopulmonar } \\
\text { pode melhorar habilidades dos } \\
\text { enfermeiros para realizar } \\
\text { ressuscitação de alta qualidade }\end{array}$ & $\begin{array}{l}\text { Estudo } \\
\text { descritivo, } \\
\text { qualitativo }\end{array}$ & Simulação & $\begin{array}{l}48 \text { enfermeiros tiveram os } \\
\text { dados coletados. } \\
\text { porcentagem mediana de tempo } \\
\text { no intervalo alvo melhorou de } \\
29 \% \text { sem treinamento para } 46 \% \\
\text { após } 1 \text { sessão, } 54 \% \text { após } 2 \\
\text { sessões, } 68 \% \text { após } 3 \text { sessões e } \\
74 \% \text { após } 4 \text { sessões ( } \mathrm{P}= \\
0,001) \text {. }\end{array}$ & $\begin{array}{lr}\text { Este programa } & \text { de } \\
\text { treinamento } & \text { em } \\
\text { ressuscitação } & \\
\text { cardiopulmonar } & \text { rendeu } \\
\text { uma } & \text { melhora } \\
\text { significativa } & \text { nas } \\
\text { habilidades e retenção. }\end{array}$ & 4 \\
\hline 10 & $\begin{array}{l}\text { MEGAN BY D, et al., } \\
\text { 2016/ EUA/ } \\
\text { CINAHL }\end{array}$ & $\begin{array}{l}\text { Implementing an In Situ } \\
\text { Mock Code Quality } \\
\text { Improvement Program }\end{array}$ & $\begin{array}{l}\text { Aumentar os níveis de } \\
\text { confiança e melhorar o } \\
\text { desempenho de enfermagem } \\
\text { durante emergências médicas } \\
\text { via em simulação situ. }\end{array}$ & $\begin{array}{l}\text { Estudo } \\
\text { descritivo, } \\
\text { qualitativo }\end{array}$ & Simulação & $\begin{array}{l}\text { Naqueles } 2 \text { anos, os tempos de } \\
\text { resposta da equipe de } \\
\text { enfermagem para pedir ajuda } \\
\text { melhorou } 12 \% \text {, tempo decorrido } \\
\text { antes o início das compressões } \\
\text { melhorou } 52 \% \text { e o tempo para } \\
\text { inicializar a desfibrilação } \\
\text { melhorou } 37 \% \text {. }\end{array}$ & $\begin{array}{l}\text { Os códigos de simulação } \\
\text { in situ melhoram } \\
\text { significativamente os } \\
\text { tempos de resposta e } \\
\text { aumentaram os níveis de } \\
\text { confiança da equipe. }\end{array}$ & 4 \\
\hline
\end{tabular}




\begin{tabular}{|c|c|c|c|c|c|c|c|c|}
\hline $\mathbf{N}^{\circ}$ & $\begin{array}{c}\text { Autor/Ano/ } \\
\text { País/Base de } \\
\text { dados indexada }\end{array}$ & Título & Objetivo & $\begin{array}{l}\text { Tipo de } \\
\text { estudo }\end{array}$ & $\begin{array}{l}\text { Estratégia } \\
\text { Tecnológica } \\
\text { para ensino }\end{array}$ & Resultados & Conclusões & $\begin{array}{l}\text { Níveis de } \\
\text { evidências }\end{array}$ \\
\hline 11 & $\begin{array}{l}\text { KOBAYASHI LEO, et } \\
\text { al., 2010/ Europa/ } \\
\text { SCOPUS }\end{array}$ & \begin{tabular}{lr} 
In Situ & \multicolumn{1}{r}{ Simulation } \\
Comparing In-Hospital \\
First Responder & Sudden \\
Cardiac & Arrest \\
Resuscitation & Using \\
Semiautomated & \\
Defibrillators & and \\
Automated & External \\
Defibrillators &
\end{tabular} & $\begin{array}{lcc}\text { Examinar o } & \text { desempenho } & \text { da } \\
\text { desfibrilação } & \text { através } & \text { de } \\
\text { cenários médicos simulados. }\end{array}$ & $\begin{array}{l}\text { Estudo } \\
\text { descritivo, } \\
\text { qualitativo }\end{array}$ & Simulação & $\begin{array}{l}\text { Não houve diferenças } \\
\text { significativas em dados } \\
\text { demográficos, experiência de } \\
\text { enfermagem ou desempenho } \\
\text { anterior de desfibrilação entre } \\
\text { os grupos de estudo. }\end{array}$ & $\begin{array}{l}\text { A simulação in situ pode } \\
\text { fornecer informações } \\
\text { úteis, tanto antecipadas } \\
\text { quanto inesperado, para } \\
\text { orientar as decisões } \\
\text { sobre tecnologias de } \\
\text { desfibrilação. }\end{array}$ & 4 \\
\hline 12 & $\begin{array}{l}\text { O'LEARY FM, 2012/ } \\
\text { Austrália/ } \\
\text { MEDLINE }\end{array}$ & $\begin{array}{l}\text { Paediatric resuscitation } \\
\text { training: Is e-learning the } \\
\text { answer? A before and } \\
\text { after pilot study }\end{array}$ & $\begin{array}{l}\text { Determinar se um programa de } \\
\text { reanimação por e-learning foi } \\
\text { capaz de melhorar o } \\
\text { conhecimento e a competência } \\
\text { de médicos e enfermeiras no } \\
\text { fornecimento de ressuscitação } \\
\text { cardiopulmonar a crianças em } \\
\text { uma parada cardíaca simulada. }\end{array}$ & $\begin{array}{l}\text { Estudo } \\
\text { descritivo, } \\
\text { qualitativo }\end{array}$ & Simulação & $\begin{array}{l}\text { O módulo de e-learning levou a } \\
\text { uma melhoria na capacidade } \\
\text { dos participantes de realizar } \\
\text { BLS por } 51 \%(P<0,001) \text { e ALS } \\
\text { por } 57 \%(P=0,001) \text { em geral, } \\
\text { resultando em em } r \text { uma } \\
\text { competência geral de } 89 \% \\
\text { (BLS) e } 65 \% \text { (ALS). }\end{array}$ & $\begin{array}{l}\text { O e-learning melhora } 0 \\
\text { conhecimento e } \quad \text { a } \\
\text { competência de médicos } \\
\text { e enfermeiras no no } \\
\text { fornecimento r de } \\
\text { ressuscitação r para } \\
\text { cardiopulmonar a } \\
\text { crianças no ambiente de } \\
\text { simulação. }\end{array}$ & 4 \\
\hline 13 & $\begin{array}{l}\text { ALLAN C, et al., } \\
\text { 2010/ EUA/ } \\
\text { SCOPUS }\end{array}$ & $\begin{array}{l}\text { Simulation-based training } \\
\text { delivered directly to the } \\
\text { pediatric cardiac } \\
\text { intensive care unit } \\
\text { engenders preparedness, } \\
\text { comfort, and decreased } \\
\text { anxiety among } \\
\text { multidisciplinary ams } \\
\text { resuscitation teams }\end{array}$ & $\begin{array}{lll}\text { Determinar os } & \text { efeitos sobre o } \\
\text { conforto e a } & \text { confiança dos } \\
\text { participantes } & \text { em relação } \\
\text { participação } & \text { em } & \text { futuras } \\
\text { ressuscitações. } & & \end{array}$ & $\begin{array}{l}\text { Estudo } \\
\text { descritivo, } \\
\text { qualitativo }\end{array}$ & Simulação & $\begin{array}{l}\text { Houve uma melhora significativa } \\
\text { na capacidade percebida dos } \\
\text { participantes de funcionar como } \\
\text { um código membro da equipe e } \\
\text { confiança em um código ( } P \\
<0,001) \text {. }\end{array}$ & $\begin{array}{l}\text { Desenvolvemos um } \\
\text { programa de treinamento } \\
\text { de Gerenciamento de } \\
\text { Recursos de Crise em } \\
\text { uma unidade de terapia } \\
\text { intensiva cardíaca } \\
\text { pediátrica para ensinar } \\
\text { habilidades técnicas de } \\
\text { ressuscitação e melhorar } \\
\text { o funcionamento da } \\
\text { equipe. }\end{array}$ & 4 \\
\hline 14 & $\begin{array}{l}\text { O'DONNELL CM, } \\
\text { SKINNER AC, 1993/ } \\
\text { Reino Unido/ } \\
\text { SCOPUS }\end{array}$ & $\begin{array}{l}\text { An evaluation of a short } \\
\text { course in resuscitation } \\
\text { training in a district general } \\
\text { hospital }\end{array}$ & $\begin{array}{l}\text { Avaliar o treinamento de } \\
\text { ressuscitação cardiopulmonar, } \\
\text { compreendendo por curta aula } \\
\text { expositiva e treinamento } \\
\text { prático. }\end{array}$ & $\begin{array}{l}\text { Estudo } \\
\text { descritivo, } \\
\text { qualitativo }\end{array}$ & Simulação & $\begin{array}{l}\text { A taxa de falha no retorno foi } \\
\text { alta, com apenas } 44 \text { dos } 100 \\
\text { enfermeiros, concluindo as } \\
\text { partes teóricas e } 60 \% \text { as partes } \\
\text { práticas do estudo. }\end{array}$ & $\begin{array}{lr}\text { A estratégia } & \text { educativa } \\
\text { resultou em } & \text { melhorias } \\
\text { significativas r } & \text { no } \\
\text { processo de ensino com } \\
\text { um aumento no } \\
\text { conhecimento r dos } \\
\text { profissionais. }\end{array}$ & 4 \\
\hline 15 & $\begin{array}{l}\text { MARTINS AR, et al., } \\
\text { 2020/ Brasil/ } \\
\text { SCOPUS }\end{array}$ & $\begin{array}{l}\text { Ensino de ressuscitação } \\
\text { cardiopulmonar através de } \\
\text { vídeo-aula }\end{array}$ & $\begin{array}{l}\text { Levantar o conhecimento sobre } \\
\text { a ressuscitação cardiopulmonar } \\
\text { no adulto utilizando a estratégia } \\
\text { da vídeo-aula }\end{array}$ & $\begin{array}{l}\text { Estudo } \\
\text { quase- } \\
\text { experimental }\end{array}$ & Vídeo-aula & $\begin{array}{l}\text { Observou-se que } 51,6 \% \text { dos } \\
\text { entrevistados } \\
\text { corretamente ao questionário } \\
\text { antes da capacitação e, após a } \\
\text { capacitação, evidenciou-se um } \\
\text { acerto de } 59,3 \% \text {. }\end{array}$ & $\begin{array}{l}\text { Detectou-se um aumento } \\
\text { no conhecimento dos } \\
\text { participantes após a } \\
\text { estratégia de ensino com } \\
\text { o uso da vídeo-aula. }\end{array}$ & 3 \\
\hline
\end{tabular}

Fonte: Braga ST, et al., 2021. 
De uma forma geral, os estudos analisados tiveram por objetivo, descrever o ensino de ressuscitação cardiopulmonar por meio de tecnologias educacionais, identificando as tecnologias educacionais utilizadas para treinamentos da equipe de enfermagem sobre ressuscitação cardiopulmonar e verificar a influência destas tecnologias para aprimoramento de saberes sobre ressuscitação cardiopulmonar e repercussão na qualidade da assistência.

Mediante a análise da amostra, observou-se, que sete dos estudos estão em língua inglesa, sete em português e um na língua espanhola. Sobre o país, identificaram-se oito estudos no Brasil, três nos EUA, dois Austrália, um estudo no Reino Unido e um na Europa. Quanto às bases indexadas, foram: cinco estudos na SCOPUS; seis na LILACS; três na CINAHL e um na MEDLINE.

Quanto à estratégia tecnológica utilizada para ensino, se destacou onze estudos referente a simulação, dois estudos quanto a produção tecnológica por vídeo-aula, três por aplicação de questionário e checklist. $O$ nível de evidência dos estudos se resultou em dez estudos de nível 4: comprovação de pesquisa descritivas (não-empírico) ou com embasamento qualitativo, seguido de quatro estudos do nível 3: elucidação de análise de artigos quase-experimentais e de um de nível 2: demonstração obtidas em estudos individuais com esboço experimental.

Os objetivos propostos pelos estudos estão relacionados ao aprimoramento de conhecimentos e desenvolvimento de habilidades com sete estudos, cinco referentes à avaliação de impacto e três relacionados a competências e atitudes.

O uso de tecnologias educacionais no processo de ensino-aprendizagem é considerado um significativo avanço, visto que as tecnologias fazem parte do cotidiano e facilitam o acesso às informações. $O$ nível de conhecimento de enfermeiros antes e após um treinamento teórico-prático resultou em melhoria do conhecimento após o curso (MARTINS AR, et al., 2020; BERTOGLIO VM, et al., 2008).

O processo de aprendizado é visto como um fator importante, quando não há destreza no atendimento sistematizado e apto a uma PCR, pode ocorrer falhas e aumento no número de iatrogenias. O processo de ensino-aprendizagem da técnica de RCP tem alto grau de complexidade, a identificação e ritmos de PCR e o conhecimento acerca das medidas de suporte básico na reanimação cardiopulmonar são variáveis importantes para qualidade na assistência (MEIRA JÚNIOR LE, et al., 2016).

Foi realizada uma pesquisa em Unidade de Terapia Intensiva (UTI), com a intenção de medir o grau de aprendizado dos profissionais em PCR e RCP, constatou-se que o grau de formação do profissional influiu no índice de acertos: técnicos de enfermagem $(78,9 \%)$, enfermeiros $(85 \%)$ já os auxiliares de enfermagem oberam o melhor resultado $(131,2 \%)$. Essas informações reforçam a necessidade da organização da educação continuada em saúde como uma ferramenta que irá favorecer a melhoria nos índices de uma RCP de qualidade (LIMA SG, et al., 2009; IRELAND S, et al., 2020).

$\mathrm{O}$ treinamento baseado em simulação há muito tempo é pensado para melhorar a função da equipe em situações clínicas de alta qualidade. Os seus resultados proporcionam melhoria na autopercepção de confiança e preparação entre os membros da equipe. O e-learning também chamado de ensino eletrônico corresponde a um modelo de ensino não presencial apoiado em tecnologia de informação e comunicação, com o objetivo de melhorar as habilidades de ressuscitação de médicos e enfermeiras, de seus autorrelato, conhecimento e confiança em fornecer uma assistência de qualidade (ALLAN CK, et al., 2010; O'LEARY FM, 2012).

Em base a síntese descritiva dos achados, foi possível categorizar os resultados da pesquisa, respondendo aos objetivos do estudo em duas categorias: $O$ ensino de ressuscitação cardiopulmonar por meio de tecnologias educacionais e a influência destas tecnologias educacionais para aprimoramento de saberes sobre ressuscitação cardiopulmonar e repercussão na qualidade da assistência.

\section{0 ensino de ressuscitação cardiopulmonar por meio de tecnologias educacionais}

Considera-se de extrema importância estimar o aprendizado da equipe de Enfermagem a respeito das diretrizes e procedimentos na PCR e suas condutas na RCP, pois, ainda que reconheçam o tema, muitos 
dos profissionais podem não ter sapiência sobre a sequência ideal no atendimento preconizado pelas diretrizes da AHA (ESPÍNDOLA MCM, et al., 2017).

O uso de tecnologias no processo de ensino-aprendizagem insigne um importante avanço, dado que as tecnologias facilitam no desenvolvimento de informações. Os treinamentos práticos quando desenvolvidos por meio de um de um processo dinâmico e baseados em estudos, viabiliza discussões e questionamentos, proporcionando a titulação profissional (SILVA AC, 2016).

A aplicação de mídias, como vídeos, no processo educacional, converte-se em um instrumento indispensável na promoção na qualidade do ensino. Destaca-se que a técnica de educação, com o uso de tecnologias, promove melhorias no processo de capacitação e gera inspiração aos participantes e, contribuise diretamente no acolhimento inicial prestado ao paciente (EVERETT-THOMAS R, et al., 2016).

A aula expositiva por vídeo é um fator diferencial no processo ensino a RCP, por meio destes, é possível contatar resultados promissores no desenvolvimento cognitivo, social e emocional, bem como na prática educacional diária. Os autores descrevem em seu estudo que ações educativas com uso de tecnologias podem surpreender positivamente nas aptidões clínicas, desenvolvendo não só a ciência, mas também, distintas habilidades, o que oportuniza uma aprendizagem relevante. Esses aspectos podem auxiliar os profissionais a sanar suas principais necessidades e dúvidas (ALVES MG, et al., 2019).

Sobre o ensino em RCP por meio de vídeos, os autores descrevem que há um acréscimo na obtenção de conhecimento e disposição usando este método como estratégia de ensino, desse modo destaca-se sua relevância para o processo de aprendizagem em ressuscitação cardiopulmonar, o estudo evidenciou que o ensino por vídeo torna-se mais eficaz que o verbal e aumenta o desenvolvimento de habilidades (SPENCE $A D$, et al., 2016).

A simulação tem sido bastante utilizada com finalidade de tomada de decisão clínica de modo que possibilite a atuação segura. É uma estratégia de treinamento que desenvolve competência no âmbito do conhecimento, habilidade e atitude, necessários ao exercício da profissão que tem como objetivo determinar o intervalo de treinamento e desenvolver habilidades em RCP, contribuindo para a operacionalização da educação continuada em enfermagem (KOBAYASHI RM e ARAÚJO GD, 2019).

$\mathrm{Na}$ formação em Enfermagem, o uso da simulação, com uso de suas tecnologias, estimula a proatividade dos discentes, além de minimizar práticas que põem em risco a segurança do paciente. $O$ uso de práticas laboratoriais simuladas acarreta para as instituições elevado desempenho técnico, científico e humano de seus alunos (COSTA RRO, et al., 2015).

Para trabalhar com as tecnologias educacionais, é preciso que o professor seja um instrumento no processo de preparação, e os participantes dessa estratégia utilizem os conhecimentos, e a criatividade na busca do crescimento pessoal e profissional. É incontestável evidenciar que a tecnologia educacional é um constituinte importante de instrumento de trabalho no exercício educativo (NIETSCHE EA, et al., 2005).

\section{A influência destas tecnologias educacionais para aprimoramento de saberes sobre ressuscitação cardiopulmonar e repercussão na qualidade da assistência}

A tecnologia educacional compreende-se por um conjunto de métodos científicos que torna capaz o planejamento de ideais, a execução e o acompanhamento educacional de forma real e informal. As constantes mudanças com ênfase na segurança do paciente mostram a necessidade de capacitação dos profissionais para a garantia da qualidade da assistência prestada à população (NIETSCHE EA, et al., 2005).

Percebe-se que a utilização de tecnologias educacionais, auxilia o profissional e organiza o atendimento prestado, melhorando a qualidade da assistência e sobrevida do paciente nas situações de emergência como uma PCR e pode diminuir o tempo de internação e seus custos. Durante as situações de emergência como a PCR, a equipe de enfermagem, tem a obrigação de dominar o conhecimento e ter preparo técnico, assim como, acesso a materiais tecnológicos, para alcançar atendimento de qualidade ao paciente em PCR (LISBOA NS, et al., 2016). 
A simulação traz como estratégia a utilização de tecnologias como recurso para reproduzir cenários práticos que se aproximem o máximo da realidade. $O$ ensino simulado trabalha com a representação de ambientes reais com a finalidade de melhoria da aprendizagem, progresso das competências, realização de avaliação, avanço no conhecimento de sistemas e ações e obtenção de destrezas na execução de procedimentos. Apresenta ainda como benefício a possibilidade da aprendizagem criativa, onde 0 aluno/profissional associa novas ideias, interagindo com novas tecnologias, compartilhando uma aprendizagem participativa (COSTA RRO, et al., 2018).

Nos últimos anos, surgiram muitos progressos nos métodos para o atendimento das emergências cardiovasculares, entre as quais se destaca a ocorrência dos Times de Resposta Rápida (TRR). A implementação dos TRR tem revelado uma eficácia na prevenção de PCR, como também contribui para a redução das taxas de letalidade hospitalar e no acolhimento em UTI, sejam pacientes adultos ou crianças (DEVITA MA, et al., 2006).

Em um estudo utilizado um teste embasado nas ações de reconhecimento e atendimento da PCR, de acordo com as diretrizes da American Heart Association (AHA), o programa foi incorporado ao escopo do TRR da instituição, com intuito de utilizar os indicadores de atendimento do grupo para subsidiar os treinamentos e garantir a melhoria contínua da assistência. O TRR além de atuar no atendimento das situações em PCR, pode corroborar no processo educativo da equipe multiprofissional, capacitando-os (VEIGA VC, et al. 2013).

O uso de vídeos é uma tecnologia valiosa no ensino, pois motiva os profissionais para aprendizagem. Com o uso de vídeos educativos almeja-se a possibilidade de um ensino inovador, favorecendo a aquisição ou atualização do conhecimento. Em um estudo foi avaliado e demonstraram que os vídeos agregam benefícios e são determinantes na formação de conhecimento (LEE N, et al., 2016; FERREIRA MVF, et al., 2015; ROLAND D, et al. 2015).

\section{CONSIDERAÇÕES FINAIS}

Este estudo demonstrou um aumento significativo no conhecimento da equipe de enfermagem após a estratégia de ensino sobre ressuscitação cardiopulmonar, utilizando as tecnologias educacionais, em cada estudo. Os estudos comprovam que as tecnologias educacionais utilizadas, promoveu o desenvolvimento de conhecimentos, de atitude e habilidade com atualizações e que através deles os profissionais de enfermagem se sentiram mais confiantes na prestação de cuidados ao paciente após o atendimento nas estações de trabalho de ressuscitação, registrando impacto positivo das tecnologias utilizadas como estratégia de aprendizagem. Nesse ínterim, o processo de ensino-aprendizagem exige constantemente a implantação de novas estratégias educativas na formação de profissionais. Assim, é fundamental que as instituições de ensino se comprometam com as transformações do perfil dos profissionais de saúde, utilizando propostas que tragam o desenvolvimento de competências e habilidades para as práticas diárias.

\section{REFERÊNCIAS}

1. ALLAN CK, et al. Simulation-based training delivered directly to the pediatric cardiac intensive care unit engenders preparedness, comfort, and decreased anxiety among multidisciplinary resuscitation teams. The Journal of Thoracic and Cardiovascular Surgery, 2010;140(3): 646-652.

2. ALVES MG, et al. Construção e validação de videoaula sobre ressuscitação cardiopulmonar. Revista Gaúcha de Enfermagem, 2019; 40: e20190012.

3. AMERICAN HEART ASSOACIATION (AHA) Resources for CPR Training \& Resuscitation. COVID-19. Content: An AHA Compendium. 2020. Disponível em: <https://professional.heart.org/professional/General/UCM_505868_COVID19-Professional-Resources.jsp>. Acesso em: 07 de agosto de 2021.

4. ASSALIN ACB, et al. An In Loco Theoretical and Practical Training Program for Nursing Professionals Regarding the Basic Maneuvers in Cardiopulmonary Resuscitation / Programa de Treinamento Teórico/Prático In Loco para Enfermagem Acerca das Manobras Básicas em Ressuscitação Cardiopulmonar. Revista de Pesquisa Cuidado é Fundamental Online, 2019; 11(2): 495-501.

5. BERNOCHE C, et al. Atualização da Diretriz de Ressuscitação Cardiopulmonar e Cuidados Cardiovasculares de Emergência da Sociedade Brasileira de Cardiologia - 2019. Arquivos Brasileiros de Cardiologia, 2019. 
6. BERTOGLIO VM, et al. Tempo decorrido do treinamento em parada cardiorrespiratória e o impacto no conhecimento teórico de enfermeiros. Revista Gaúcha de Enfermagem, 2008; 29(3): 454.

7. BISHOP R, et al. Automated Audiovisual Feedback in Cardiopulmonary Resuscitation Training: Improving Skills in Pediatric Intensive Care Nurses. Critical Care Nurse, 2018; 38(5): 59-66.

8. COSTA RRO, et al. O uso da simulação no contexto da educação e formação em saúde e enfermagem: uma reflexão acadêmica. Espaço para Saúde, 2015; 16(1): 59-65.

9. COSTA RRO, et al. A simulação no ensino de enfermagem: uma análise conceitual. Revista de Enfermagem do Centro-Oeste Mineiro, 2018; 8(0).

10. DEVITA MA, et al. Findings of the first consensus conference on medical emergency teams. Crit Care Med, 2006; 34(9): 2463-78.

11. ESPÍNDOLA MCM, et al. Parada cardiorrespiratória: conhecimento dos profissionais de enfermagem em uma unidade de terapia intensiva. Rev enferm UFPE on line 2017 ; 2773-2778.

12. EVERETT-THOMAS R, et al. An assessment of CPR skills using simulation: Are first responders prepared to save lives? Nurse Education in Practice, 2016; 19(0): 58-62.

13. FERREIRA MVF, et al. Lights, camera and action in the implementation of central venous catheter dressing. Revista Latino-Americana de Enfermagem, 2015; 23(6): 1181-1186.

14. IRELAND S, et al. Emergency nurses' experience of adult basic and advanced life support workstations as a support strategy for clinical practice in the emergency department. Australasian Emergency Care, 2020; 23(2): 77-83.

15. MEIRA JÚNIOR LE, et al. Avaliação de treinamento em suporte básico de vida para médicos e enfermeiros da atenção primária. Revista Brasileira de Medicina de Família e Comunidade, Rio de Janeiro, 2016; 11(38): 1-10.

16. KOBAYASHI RM, ARAÚJO GD. Avaliação do treinamento mediado por tecnologias educacionais: revisão integrativa. Journal of Health Informatics, 2019; 11(3).

17. KOBAYASHI LEO, et al. In Situ Simulation Comparing In-Hospital First Responder Sudden Cardiac Arrest Resuscitation Using Semiautomated Defibrillators and Automated External Defibrillators. Simulation in Healthcare: The Journal of the Society for Simulation in Healthcare, 2010; 5(2): 82-90.

18. LEE NJ, et al. Mobile-Based Video Learning Outcomes in Clinical Nursing Skill Education: A Randomized Controlled Trial. CIN: Computers, Informatics, Nursing, 2016; 34(1): 8-16.

19. LIMA SG, et al. Educação Permanente em SBV e SAVC: impacto no conhecimento dos profissionais de enfermagem. Arquivos Brasileiros de Cardiologia, 2009; 93(6): 630-636.

20. LISBOA N, et al. Avaliação do conhecimento dos enfermeiros sobre os cuidados pós-parada cardiorrespiratória. Revista de Enfermagem UFPE on line, 2016; 10(10): 3778-3786.

21. MARTINS AR, et al. Ensino de ressuscitação cardiopulmonar por meio de videoaula. Revista de Enfermagem UFPE on line, 2020; 14(0).

22. MENDES KDS, et al. Revisão integrativa: método de pesquisa para a incorporação de evidências na saúde e na enfermagem. Texto \& Contexto - Enfermagem, 2008; 17(0): 758-764.

23. MELNYK T, et al. A importância da prática da psicologia baseada em evidências: aspectos conceituais, níveis de evidência, mitos e resistências. Revista Costarricense de Psicología, 2014; 33(2): 79-92.

24. NIETSCHE EA, et al. Education, care and management technologies: a reflection based on nursing teachers' conception. Revista Latino-Americana de Enfermagem, 2005; 13(3): 344-352.

25. O'DONNELL CM, SKINNER AC. An evaluation of a short course in resuscitation training in a district general hospital. Resuscitation, 1993; 26(2): 193-201.

26. O'LEARY FM. Paediatric resuscitation training: is e-learning the answer? A before and after pilot study. Journal of Paediatrics and Child Health, 2012; 48(6): 529-533.

27. PIMENTEL TGB. Assistência de enfermagem ao paciente com sepse em unidades de terapia intensiva. Revista Científica Multidisciplinar Núcleo do Conhecimento, 2019; 5(5): 05-16.

28. PINHEIRO WR, et al. Utilização do Protocolo de Registro Utstein durante as Manobras de Reanimação Cardiopulmonar: Revisão Integrativa / Use of the Utstein Protocol Record during the Cardiopulmonary Resuscitation Maneuver: Integrative Review. ID on line. Revista de psicologia, 2020; 14(49): 478-488.

29. PISCIOTTANI F, et al. In situ simulation in cardiopulmonary resuscitation: Implications for permanent nursing education. J Nurs UFPE on line, 2017; 11(7): 2810-5.

30. ROLAND D, et al. Is perception of quality more important than technical quality in patient video cases? BMC Medical Education, 2015; 15(1): 132.

31. SANGUINO GZ. Desenvolvimento de material educativo para manejo da parada cardiorrespiratória pediátrica ocasionada por insuficiência respiratória. Universidade de São Paulo, 2019.

32. SILVA AC, et al. Development of a virtual learning environment for cardiorespiratory arrest training*. Revista da Escola de Enfermagem da USP, 2016; 50(0): 00990-00997.

33. SOUZA MT, et al. Revisão integrativa: o que é e como fazer. Einstein (São Paulo), 2010; 8(0): 102-106.

34. SPENCE AD, et al. Does video feedback analysis improve CPR performance in phase 5 medical students? BMC Medical Education, 2016; 16(1): 203.

35. VEIGA VC, et al. Atuação do Time de Resposta Rápida no processo educativo de atendimento da parada cardiorrespiratória. Revista da Sociedade Brasileira de Clínica Médica, 2013; 11(3): 258-262. 